\title{
Modification of Drosophila Cell Surfaces by Concanavalin $\mathrm{A}^{*}$
}

\author{
R.M. Rizki, T.M. Rizki, and Ch.A. Andrews** \\ Division of Biological Sciences, The University of Michigan, Ann Arbor, Michigan, USA
}

\begin{abstract}
Summary. The effect of Con A on the surface morphology of cultured cells of Drosophilia melanogaster growing on coverglasses was examined by scanning electron microscopy. With low lectin concentrations $(5-10 \mu \mathrm{g} / \mathrm{ml})$ surface filaments disappeared and the cells flattened and spread against the glass surface. Cytoplasmic fusion bridges were observed in areas where cells made contact. Concentrations of Con A ranging between $50-500 \mu \mathrm{g} / \mathrm{ml}$ caused cell shrinkage and surface distortions without cell flattening and filament loss. These morphologic effects were not apparent if Con A binding sites were blocked by preincubation with $\alpha$-methyl-D-mannopyranoside before application to the cell cultures. However, once the Con A-mediated changes were in effect, the cells failed to show recovery when they were returned to growth medium and a majority of the cells on the coverglasses degenerated. Presumably the cells whose morphology appears unaffected by Con A treatment are the survivors that repopulate cultures returned to growth medium.
\end{abstract}

Key words: Concanavalin A - Drosophila cells - Cell surface - Cell fusion.

\section{Introduction}

In recent years plant lectins have been utilized extensively to investigate surface properties of the cell. This interest in lectins stems primarily from the observation that transformed tissue culture cells are preferentially agglutinated by interaction with these proteins, suggesting that surface properties of the transformed cell differ in certain respects from those of its untransformed counterpart (Inbar and Sachs,

Send offprint requests to: Dr. T.M. Rizki, The University of Michigan, Division of Biological Sciences, Ann Arbor, Michigan 48109, USA

* Supported by Grants CA-12600 and CA 16619 awarded by the National Cancer Institute, DHEW and in part by NIH Biomedical Sciences Grant No. RR-07050. CAA's participation in this project was supported by Training Grant No. 5T01-GM-71-17

** We wish to thank Dr. Imogene Schneider for providing the cell lines 
1969; Noonan and Burger, 1973). Of the numerous lectins identified, Concanavalin A (Con A) has been the most widely used and studied (Sharon and Lis, 1972). Con A interacts to form a precipitate with carbohydrates possessing terminal nonreducing $\alpha$-D-glucopyranosyl or $\alpha$-D-mannopyranosyl moieties (Goldstein, et al., 1965; Poretz and Goldstein, 1970), and receptor sites for the lectin on the cell surface have been localized by using fluorescein- or ferritin-conjugated Con A (Fox et al., 1971; Nicolson and Singer, 1971; Mallucci, 1971). The mechanism underlying agglutination of cells by Con A has not been elucidated, but presumably its ability to bind to specific sugar residues on the cell membrane initiates cell clumping. Singer and Nicolson (1972) have proposed that differences in membrane topography may be related to cell agglutination since a random or uniform distribution of receptor sites is found in cells that are not agglutinated whereas cells that are susceptible to agglutination show a clustering or a patchy localization of receptors (Nicolson, 1972).

A quantitative comparison of the Con A-induced agglutinability of three Drosophila cell lines has revealed minor differences among the lines (Andrews and Rizki, submitted for publication). There is however, an additional feature of interest in the response of Drosophila cells to lectin treatment. Both Con A (Becker, 1972; Halfer and Petrella, 1976) and wheat germ agglutinin (Rizki et al., 1975) induce fusion as well as agglutination of these cells. In the studies with Con A, light microscopy and autoradiography were used to visualize fusion of isotopically labelled and unlabelled cells; in the study with wheat germ agglutinin scanning electron microscopy was employed to observe changes in the surface morphology of cells exposed to the lectin. Mechanical agitation to achieve cell contact was avoided in the latter study. Rather, the response to wheat germ agglutinin was tested by treating cells growing on coverglasses. In the presence of the lectin the cells flattened against the substratum and fused as they met. Such morphological distortions were not affected by simultaneous exposure to $\mathrm{N}$-acetyl-glucosamine, the inhibitor usually employed to block cell agglutination by wheat germ agglutinin. We, therefore, decided to examine the effects of Con A and one of its specific inhibitors on the surface morphology of Drosophila cells growing on a solid substrate. In this report we describe the results of these studies together with observations on cells recovering from Con A treatment.

\section{Materials and Methods}

The three Drosophila melanogaster cell lines originally established by Schneider (1972) were used in the present study. Methods for growing the cells and fixing for scanning electron microscopy were the same as those previously described (Rizki, et al, submitted for publication). Cell cultures were used two days after inoculation except for one experiment in which both two and seven day cultures of line 1 were examined. Concentrations of Con A (Calbiochem) ranging from $5 \mu \mathrm{g} / \mathrm{ml}$ to $500 \mu \mathrm{g} / \mathrm{ml}$ were dissolved in the phosphate-buffered saline recommended for Drosophila embryonic cells by Seecof (1971), and $\alpha$ methyl-D-mannopyranoside (Caibiochem) was used at concentrations of $20 \mathrm{mM}$ and $100 \mathrm{mM}$ in this same buffer.

In the first series of experiments two groups of cells served as controls for each of the three cell lines. Cells growing in Schneider's medium on one coverglass were flooded with formaldehyde fixative, while Schneider's medium in the other control group of cells was replaced by Seecof's saline for 30 min prior to fixation. Since the surface features of the cells in both controls did not differ, only a saline control was used for all subsequent experiments. 
Schneider's medium in which the cells were growing was removed and the cells on the coverglasses were rinsed with two changes of buffer solution. They were then covered with one milliliter of the lectin solution, or appropriate control mixture, and allowed to remain stationary for the treatment period ( 5 to $30 \mathrm{~min})$ at $24-25^{\circ} \mathrm{C}$. Care was exercised in handling the culture tubes to minimize mechanical movement, and liquids were changed by gently pipetting against the culture tube walls rather than directly on the coverglass surface in the tube. For the studies reported in this paper, material was fixed in five series such that experimental treatments were duplicated in independent runs.

\section{Results}

Effect of Con A Concentration. Many cells from each of the three Drosophila lines placed in Con A concentrations of 5 or $10 \mu \mathrm{g} / \mathrm{ml}$ for $30 \mathrm{~min}$ lost their spherical appearance and spread over the glass surface. In regions where cells were growing in close proximity and the cytoplasmic extensions of neighboring cells made contact, the surface boundaries of individual cells were no longer discrete (Figs. 1,2). This phenomenon was more apparent in lines 1 and 3 since the cells in these lines normally remain attached to the glass surface and are not contact inhibited.

Considerable variation in surface morphology was found among the cells treated with Con A. Some cells were flattened and uniformly thin as they spread against the glass surface. Other cells were slightly convex and a few cells on each coverglass remained spherical. This variability in cell response to Con A may relate to the fact that the cell cultures contain a diverse population of cells, and the degree of flattening as well as cell fusion may depend upon the stage in the growth cycle and the substrate on which the cells are resting at the time of exposure to Con $A$. These features were best exemplified by the Con A treated cells of line 1. Cells in this line are grouped in discrete colonies. In large colonies, cells in the center pile upon one another, and those on top tend to retain a spherical shape on exposure to Con $A$. The peripheral cells in these colonies that are resting on the coverglass show flattening and fusion. Interconnecting regions of layered cells were scanned at a magnification of 30,000 and no seams between the cells were detectable (Fig. 3).

The surfaces of cells treated with $50 \mu \mathrm{g}$ Con $\mathrm{A} / \mathrm{ml}$ appeared shrunken and markedly distorted. Cell distortions were even more pronounced at Con $\mathrm{A}$ concentrations of $250-500 \mu \mathrm{g} / \mathrm{ml}$. Some of the cells showed deep folds and invaginations but the cell membrane had a smooth fine texture; other cells appeared to lose their turgidity and looked shrivelled without showing any loss of surface filaments (Fig. 4). These effects of Con A on surface morphology were not lessened by shortening the treatment period to $5 \mathrm{~min}$.

Effect of a Con A Inhibitor. The cellular modifications caused by Con A were blocked by preincubation of the lectin with $\alpha$-methyl-D-mannopyranoside(MMP). Con $A(50 \mu \mathrm{g} / \mathrm{ml})$ was mixed with $100 \mathrm{mM} \mathrm{MMP}$ and allowed to stand for $10 \mathrm{~min}$. One millititer of this mixture was then added to line 3 cell cultures which were fixed $30 \mathrm{~min}$ later. The morphology was normal in treated cells as well as controls placed in $100 \mathrm{mM}$ MMP for $30 \mathrm{~min}$. This sequence was repeated in a later study in which $10 \mu \mathrm{g}$ Con $\mathrm{A} / \mathrm{ml}$ and $20 \mathrm{mM}$ MMP were used, and the effectiveness of Con A was also lost under these conditions. 

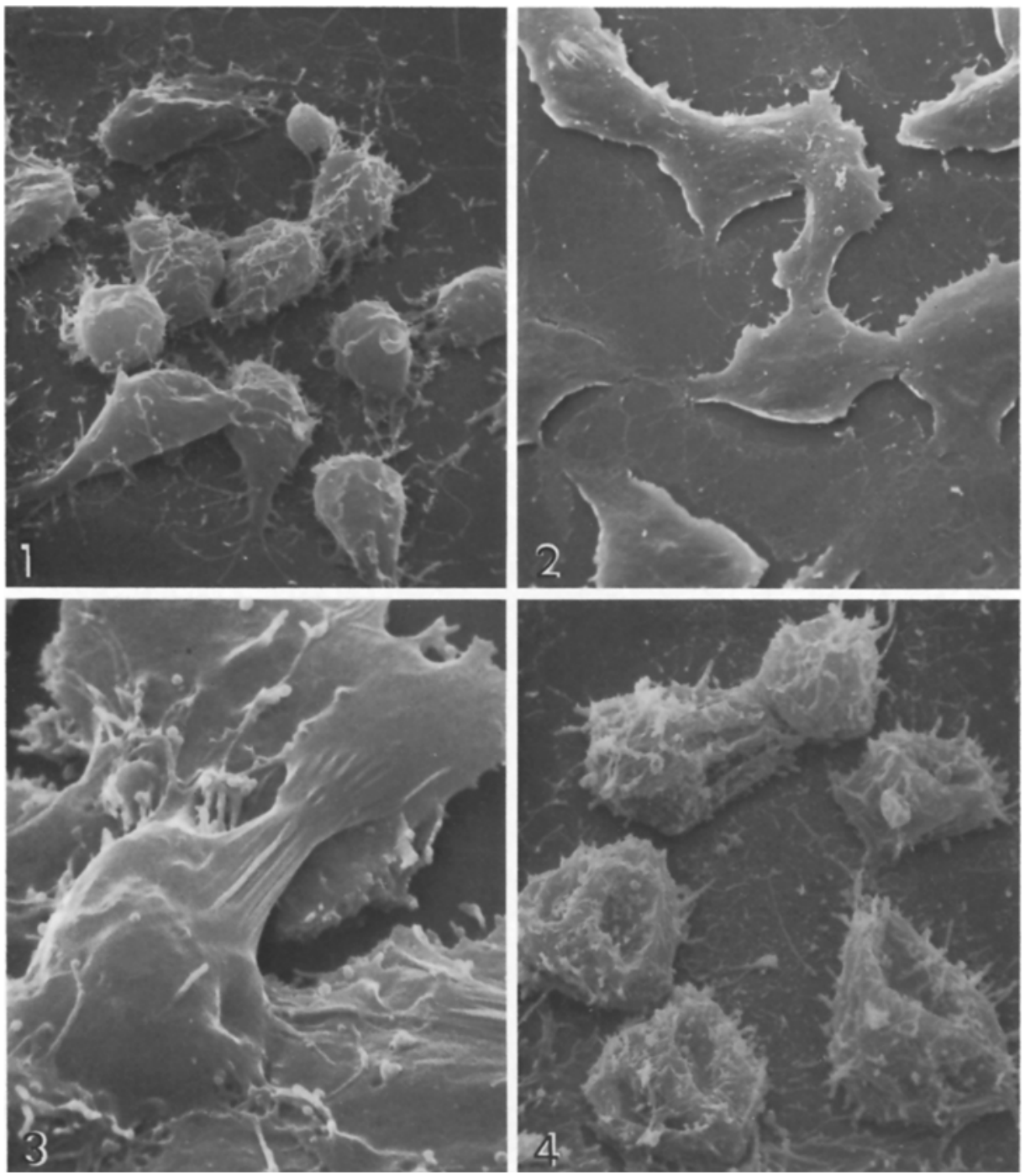

Fig. 1. Line 1 cells incubated in buffered saline for $30 \mathrm{~min} . \times 2010$

Fig. 2. Detail from line 1 colony treated with Con $\mathrm{A}(10 \mu \mathrm{g} / \mathrm{ml})$ for $30 \mathrm{~min}$ to demonstrate continuity between the cytoplasms of five cells. $\times 1940$

Fig. 3. Illustration of the stickiness observed between line 1 cells resting on other cells. Treatment as above. The stretched area between the two cells was examined at 30,000 and no evidence of discreteness of cell surface boundaries was discernible. $\times 6700$

Fig. 4. Line 3 cells treated with $250 \mu \mathrm{g} / \mathrm{ml}$ Con A for $30 \mathrm{~min}$. Cells have collapsed but retained their filaments and blebs. $\times 2680$ 

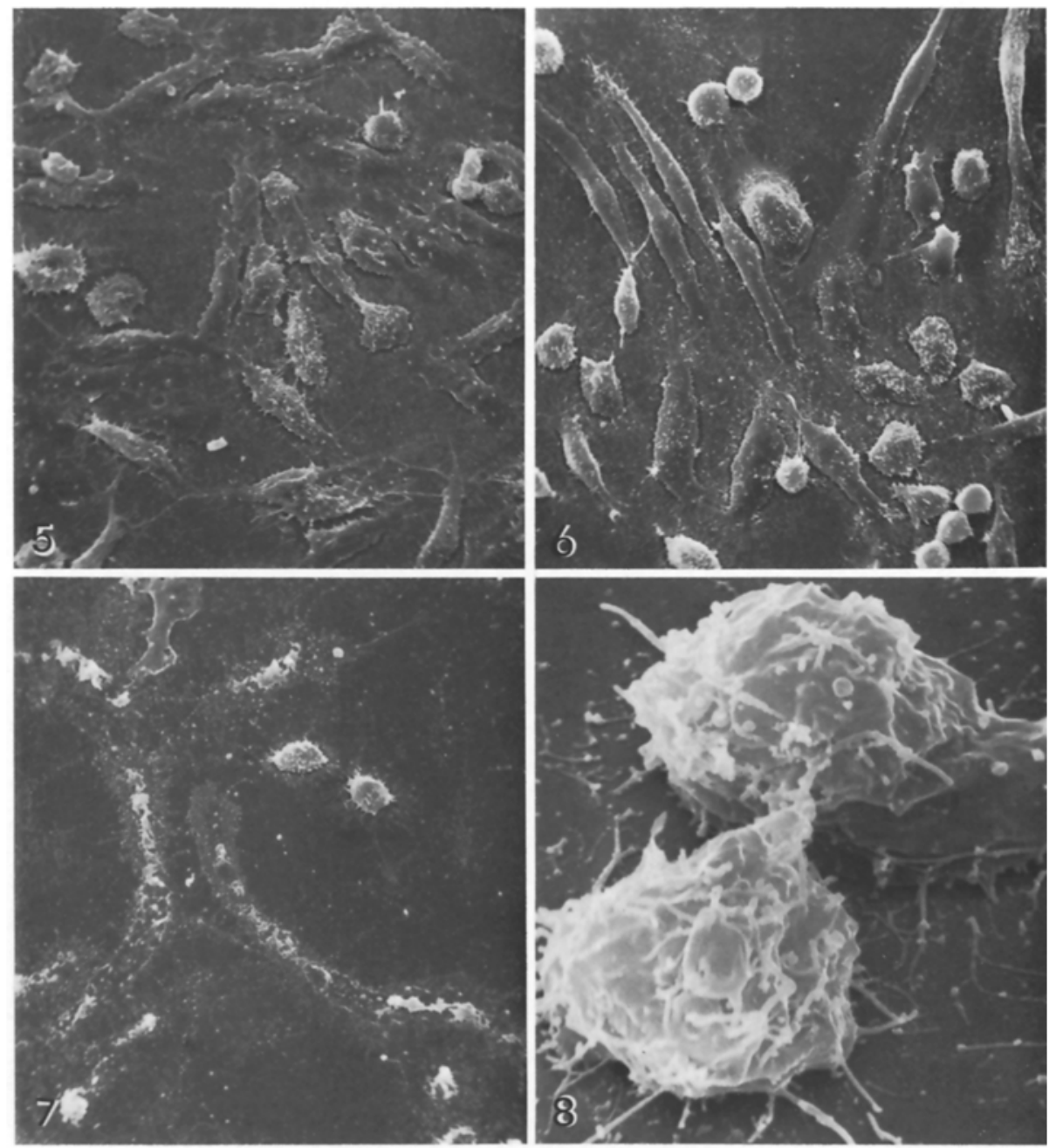

Fig. 5. Line 3 cells treated with $10 \mu \mathrm{g} / \mathrm{ml}$ Con A for $30 \mathrm{~min} . \times 750$

Fig. 6. Cells treated as above simultaneously, then rinsed with $20 \mathrm{mM} \mathrm{MMP}$ and transferred for $2 \mathrm{~h}$ to Schneider's medium to which was added $20 \mathrm{mM}$ MMP. $\times 750$

Fig. 7. Area of a coverglass from the above experiment after six additional hours. Note cellular debris and the few cells remaining after processing for SEM. $\times 750$

Fig. 8. Details of spherical cells from the experiment described in Figure 7. Note the presence of filaments and blebs, and overall normal appearance of the cells. $\times 7500$

Studies on the Reversibility of Con A Effects. Four series of experiments were undertaken to determine whether the surface changes and cell fusion caused by Con $\mathrm{A}$ are reversible following removal of the lectin. In the first experiment, line 3 cells were treated with $250 \mu \mathrm{g}$ Con $\mathrm{A} / \mathrm{ml}$ for $30 \mathrm{~min}$, rinsed with MMP, and placed in Schneider's medium for $5 \mathrm{~h}$. In the second experiment this sequence was repeated 
with $10 \mu \mathrm{g}$ Con $\mathrm{A} / \mathrm{ml}$ for $30 \mathrm{~min}$ and Schneider's medium for $6 \mathrm{~h}$. Many cells in the first experiment appeared distorted and shrivelled, and regions of coalesced cells were found. Similarly, the second experiment failed to indicate reversal of the Con A effects when cells were transferred to normal growth medium. In both experiments, however, some cells on the coverglasses showed normal morphological features. Since a few cells in Con A treated samples retain a normal appearance, the normal appearing cells in these experiments presumably represented cells that were not affected by the initial Con A treatment.

Two experiments were performed to determine whether the presence of MMP in the growth medium would influence recovery from Con A treatment. For these studies, cells were placed in $10 \mu \mathrm{g}$ Con $\mathrm{A} / \mathrm{ml}$ for $30 \mathrm{~min}$, rinsed twice with a $10 \mathrm{mM}$ solution of MMP, then transferred either to Schneider's medium or to Schneider's medium containing $20 \mathrm{mM}$ MMP. Cells were fixed after they had remained in growth medium for 2,4 , or $8 \mathrm{~h}$. These experiments did not provide any indication that Con A effects were reversible in Drosophila cells. Areas of disintegrated cells were especially pronounced on coverglasses with Con A treated cells which were allowed to remain in growth medium containing MMP (Figs. 5-8). Some evidence of cell destruction was also found on coverglasses transferred to Schneider's medium after $10 \mu \mathrm{g} / \mathrm{ml}$ Con A treatment, but more cells appeared healthy in these samples than in medium containing MMP. Control cells placed in Schneider's medium with MMP for $8 \mathrm{~h}$ appeared normal. A similar experiment was performed in which cells were treated with $50 \mu \mathrm{g}$ Con $\mathrm{A} / \mathrm{ml}$, rinsed with $\mathrm{MMP}$, and then placed for $8 \mathrm{~h}$ in Schneider's medium to which $100 \mathrm{mM}$ MMP had been added. After this treatment the cells appeared turgid and showed blebs and shortened microvilli.

\section{Discussion}

The striking morphological changes induced by Con A treatment of Drosophila cells were essentially similar in the three cell lines. All concentrations of Con A caused stickiness and intercellular binding of cells, although the surface modifications induced by high and low concentrations differed. This difference in response may be reconciled by proposing that binding of the lectin to the cell surface leads to weakened membrane structure caused by rearrangements in the stable molecular configuration of the outer cell layer. At low concentrations, the repair turnover of membrane materials involved in molecular readjustments results in cell flattening as well as the fusion of cytoplasms when two cells touch each other. At high concentrations, the instantaneous saturation of binding sites with Con A presumably results in physiologic shock and as a consequence cell permeability is altered. Under the latter conditions, rigidity of surface structure would result, so flattening and reorganization of surface components are prevented. The cells, therefore, appear collapsed and shrunken but their surface filaments and knobs are retained. This interpretation is supported by the observation that cells returned to Schneider's medium after exposure to high concentrations of Con A appeared turgid when viewed with the scanning electron microscope. 
The toxicity of Con A for cultured cells was demonstrated by Shoham, et al. (1970) who stated that the decrease in cell numbers in cultures could be due to inhibition of cell multiplication or cell killing. Our observations support the latter possibility, and it is not clear in the present study whether any of the Con A fused cells survive. That some Drosophila cells do survive Con A treatment and continue to multiply can be readily demonstrated by examining Con A treated cultures several days after they have been returned to Schneider's medium. Since a few cells on Con A treated coverglasses do not show any visible modifications when examined by scanning electron microscopy, however, it is possible that these cells are the survivors that repopulate the treated cell cultures. Cell destruction was more pronounced in cultures returned to Schneider's medium to which MMP was added than in cultures transferred to Schneider's medium without MMP. The difference between the two treatments is interesting since Noonan and Burger (1973) found that $25 \%$ of the Con A bound to mammalian cells was released when the cells were incubated with MMP for $30 \mathrm{~min}$ at $22^{\circ} \mathrm{C}$. Experimentation is required to confirm that bound Con A can be removed from Drosophila cells by incubation in MMP and to determine whether the rate of removal of bound Con $A$ in the presence and absence of MMP in Schneider's medium differs. The present study has not excluded the possibility that the stability of surface structures is modified when Con A treated cells are returned to growth medium, and the cells become too fragile to be subjected to the processing required for scanning electron microscopy.

If sensitivity to Con A differs during stages of the cell cycle, survivors may represent cells in the less sensitive periods during lectin exposure. Studies with synchronized cells indicate that more Con $\mathrm{A}$ is bound by cells in mitosis than during the interphase period (Noonan and Burger, 1973). There may not, of course, be a correlation between the amount of Con A bound to a cell and visible morphological alterations detected by scanning electron microscopy, but there was some indication in the present study that Drosophila cells at cytokinesis or shortly thereafter showed less membrane distortion than cells at other stages. In the absence of experimental evidence, however, there is also no reason to exclude the possibility that some cells in the populations are more resistant to toxic effects of Con A than other cells.

It is reasonable to consider that the aggregation of suspended cells obtained by mechanical swirling in Con A solutions (Andrews and Rizki, submitted for publication) is due to the same type of membrane reactions that occur when stationary cells are treated with Con A. Two components appear to be involved: membrane modification and agglutination/fusion. Reorganization of membrane materials is most evident at low lectin concentrations and fusion of cells is also best observed at these same concentrations. It is not clear whether there is a distinction between the processes responsible for cell fusion and cell agglutination from the present study, however. That the mechanism of Drosophila cell binding induced by Con $A$ is a similar one in stationary and rotated cultures is supported by the fact that removal of Con A does not lead to separation of cells bound under either treatment condition. Furthermore, both the fusion of cells growing on a coverglass and the clumping of cells in suspension are inhibited by preincubating the Con $\mathrm{A}$ with MMP. 


\section{References}

Becker, M.J.: Fusions in vitro de cellules somatiques en culture de Drosophila melanogaster, induites par la Concanavaline A. C.R. Acad. Sci. (Paris) 275, 2969-2972 (1972)

Fox, T.O., Sheppard, J.R., Burger, M.M.: Cyclic membrane changes in animal cells; transformed cells permanently display a surface architecture detected in normal cells only during mitosis. Proc. nat. Acad. Sci. (Wash.) 68, 244247 (1971)

Goldstein, I.J., Hollerman, C.E., Smith, E.E.: Protein-carbohydrate interaction. II. Inhibition studies on the interaction of concanavalin A with polysaccharides. Biochemistry 4, 876-883 (1965)

Halfer, C., Petrella, L.: Cell fusion induced by lysolecithin and concanavalin A in Drosophila melanogaster somatic cells cultured in vitro. Exp. Cell Res. 100, 399-404 (1976)

Inbar, M., Sachs, L.: Interaction of the carbohydrate-binding protein concanavalin A with normal and transformed cells. Proc. nat. Acad. Sci. (Wash.) 63, 1418-1425 (1969)

Mallucci, L.: Binding of concanavalin A to normal and transformed cells as detected by immunofluorescence. Nature (Lond.) New Biol. 233, 241-244 (1971)

Nicolson, G.L.: Topography of membrane concanavalin A sites modified by proteolysis. Nature(Lond.) New Biol. 239, 193-196 (1972)

Nicolson, G.L., Singer, S.J.: Ferritin-conjugated plant agglutinins as specific saccharide stains for electron microscopy: Application to saccharides bound to cell membranes. Proc. nat. Acad. Sci. (Wash.) 68, 942-945 (1971)

Noonan, K.D., Burger, M.M.: Binding of $\left({ }^{3} \mathrm{H}\right)$ concanavalin A to normal and transformed cells. J. biol. Chem. 248, 4286-4292 (1973)

Poretz, R.D., Goldstein, I.J.: An examination of the topography of the saccharide binding sites of concanavalin A and of the forces involved in complexation. Biochemistry 9, 2890-2896 (1970)

Rizki, R.M., Rizki, T.M., Andrews, C.A.: Drosophila cell fusion induced by wheat germ agglutinin. J. Cell Sci. 18, 113-121 (1975)

Schneider, I.: Cell lines derived from late embryonic stages of Drosophila melanogaster. J. Embryol. exp. Morph. 27, 353-365 (1972)

Seecof, R.L.: Phosphate-buffered saline for Drosophila. Dros. Infor. Serv. 46, 113 (1971)

Sharon, N., Lis, H.: Lectins.: Cell-agglutinating and sugar-specific proteins. Science 177,949-959(1972)

Shoham, J., Inbar, M., Sachs, L.: Differential toxicity on normal and transformed cells in vitro and inhibition of tumour development in vivo by Concanavalin A Nature (Lond.) 227, 1244-1246 (1970)

Singer, S.J., Nicolson, G.L.: The fluid mosaic model of the structure of cell membranes. Science 175, $720-731$ (1972)

Accepted August 1, 1977 